\title{
Preparation for higher education (HE): a study of collaborative partnerships in easing the transition to HE
}

\section{Helen Bussell}

Teesside University Business School, UK

\section{Lesley Mulcahy}

Teesside University Business School, UK

\begin{abstract}
This paper reports the second stage of a longitudinal study examining a successful collaborative project delivered through a partnership between institutions. The study evaluates a Level 4 module for further education (FE) students delivered jointly by Teesside University and a number of partner Colleges of Further Education (CFE) as a 'spiky profile'. The first phase of the study concentrated on 2006/07 and 2007/08. The research reported here continues the evaluation of the module looking at staff, students and curriculum content for 2008/09, taking into account macro and micro influences. It follows the progression of students from previous cohorts and also examines the scheme's expansion across the region resulting from the success of the original programme. Key points from the findings have been incorporated into a model to highlight the main areas of consideration for collaborative working between FE and higher education (HE).
\end{abstract}

Keywords: widening participation; partnership; collaboration; transition to HE; access.

\section{Introduction}

Following on from the Dearing Report, the government has shown a clear commitment to increasing the numbers of students and ensuring higher take up rates by those previously under-represented in higher education (HE) (DfIUS, 2003). In 2000 the Government stated that $50 \%$ of those between the ages of 18 and 30 should have the opportunity to benefit from higher education by the end of the decade (DfEE, 2000). Working towards this target 
has changed the student body radically. The HE initial participation rate for 2006/07 entry stood at 40\% (DfIUS, 2008) with the proportion of UK university entrants from lower socio economic groups moving upwards, albeit marginally (from 29.3\% in 2005/6 to 29.8\% 2006/7; figures for the North East were 33.1\% in 2005/06 and 34.3\% in 2006/07 (HESA, 2008)).

Stuart (2003) has argued that widening participation and fair access is something that no institution can ignore. This was reinforced by John Rushford, Director of Widening Participation at the Higher Education Funding Council for England (HEFCE), who stated that widening participation was one of HEFCE's four core strategic aims and an influential component of policy development in all areas. In the same paper he continued that widening participation would be a key theme in the corporate policies that institutions were developing over the next coming years (Rushford, 2004). However, widening participation is not just about increasing numbers it is concerned with 'changing the class bias of higher education and it is about enabling students to complete their studies successfully' (Stuart, 2003, online). This has had significant implications for both HE and FE sectors.

Aimhigher has demonstrated that progress can be achieved through collaborative work carried out by institutions working in partnership (HEFCE, 2006). Although collaborations can be viewed and interpreted in different ways by different people (Buys and Bursnall, 2007), there is evidence that collaboration increases the likelihood of organisations reaching a larger population, avoiding duplication of services and improving use of their resources (Hastad and Tymeson, 1997):

Educators are finding that one of the most powerful ways to cultivate and nurture diversity in teaching and reach a diversity of students is to combine efforts and expertise with colleagues. (Cook and Friend 1995, cited Kluth and Straut, 2003, p.228)

Studying partnerships between universities, Sargent and Waters (2004) presented a framework of academic collaboration which proposes that such partnerships go through cycles consisting of specific phases: initiation, clarification (of the project and its goals), implementation (including identification of roles and responsibilities) and completion (together with evaluation of outcomes). Collaboration is influenced by interpersonal relationships which develop between the parties and by contextual factors such as the processes introduced, 
resources and support. Interpersonal factors were also found to be the most influential factors in Buys and Bursnall's (2007) investigation of university-community collaboration. Open communications, characterised by trust, mutual respect, good humour and tolerance, helped to clarify the direction of the partnership and resolve any issues.

In recent years there has been an increase in collaborative working practices between partner colleges and universities (Jary, 2008). The government policy of mass HE has resulted in the rising importance of HE provision in Colleges of Further Education (CFE) as a means of widening access, with the consequent development of alternative progression routes and the experience of individual learners as they navigate their way through FE into HE (Smith and Bocok 1999, p.283). If students are brought into a university environment and encouraged to be involved in both the further education (FE) and HE process the students will achieve an element of confidence and knowledge of both establishments and their learning experience. Such activity breaks down barriers for students and also enhances their academic self concept (ASC), defined by Bennett (2009) as self-belief in one's academic competence, self-appreciation of one's personal worth as a student and self connection with being an undergraduate. Michie et al., (2001) suggest that a variety of teaching methods and university organisational arrangements may need to be modified in order to enable low-ASC students to attain their full educational potential.

\section{Preparation for higher education}

Such influencers are reflected in Teesside University's widening participation and community learning strategies (Teesside University, 2008) through which a programme has been developed with partner CFEs in the region whereby FE students study a Level 4 module as part of their Level 3 FE course. The notion of studying and being assessed at different levels has been defined as a 'spiky profile' (DfIUS, 2001). For EdExcel programmes a 'spiky profile' would be a National Diploma course at Level 3 with some units available at Levels 2 or 4 . As long as these units do not make up more than $25 \%$ of the qualification, the overall qualification will still be at a level 3 BTEC National standard.

This collaborative exercise, initiated by senior management at Redcar and Cleveland College (RCC), resulted in Teesside University Business School (TUBS) staff developing a 20 credit Level 4 module called Preparation for Higher Education (PHE) based on a 40 
credit Level 4 core TUBS module, Personal Development and Employability (PDE). PHE was introduced, on a trial basis with 32 students, in September 2006 and delivered at RCC largely by college staff. An integral element of PHE involved students visiting the university campus and joining activities coordinated and delivered by TUBS staff alongside Year 1 undergraduates. Students studying the module received $A P(E) L$ for 20 credits of learning if they proceeded to a TUBS programme or equivalent Teesside University course.

The main focus of PHE was to enhance research and coursework skills in preparation for $\mathrm{HE}$ requirements. A secondary aim was to remove perceived barriers to progressing to $\mathrm{HE}$ held by some RCC students and consequently encourage more students to apply to university. The module was, therefore, seen as important for the progression of students from RCC and as an element of the widening participation strategies of TUBS and Teesside University. In addition this project gave TUBS and RCC an opportunity to work collaboratively for the benefit of all.

During 2007/08 a second cohort participated in PHE at RCC and similar modules were introduced at the college in a wider range of disciplines by two other university Schools: Professional Practices (PP) by the School of Computing (SC) and Principles of EvidenceBased Practice (PEBP) by the School of Health. Other partner colleges were attracted to the scheme so that at September 2009, PHE was being offered by five CFEs to approximately 500 students. More local colleges (and even an institution in China) are interested in establishing similar programmes utilising the existing module and ways of working.

The number of applications to Teesside University from the CFEs running the module have increased year on year from 2006/07 and the percentage of these converted to acceptances has also increased from $60.97 \%$ to $65.47 \%$. These partner colleges figure prominently as feeder institutions to Teesside University, ranking $1^{\text {st }}, 9^{\text {th }}, 12^{\text {th }}$ and 14 th (Teesside University, 2010).

Due to the attention being given to PHE it was felt that a full module evaluation was required and funding was acquired through the Partnership Capacity Fund. The first stage of this was completed in 2009 focussing on the operation of the spiky profile at RCC and the student experience. Strengths of the module and challenges to be addressed were identified and recommendations for future development were presented (see Bussell and 
Mulcahy, 2009). The second stage of the evaluation included all the colleges now involved and followed through students who had progressed to HE. As there was much similarity between the two stages regarding the findings concerning the student experience, this paper concentrates on the issues around collaboration between partner colleges and Teesside University which emerged from the module evaluation. The paper examines the experiences of those involved in this maturing collaborative venture. The aim of this paper is to gain an understanding of key issues and identify practices which require further development to enable the partnership to progress and highlight to other institutions how they might proceed with similar activities.

\section{Methodology}

This paper reports on the second stage of a longitudinal study. Stage 1 examined cohorts 2006/07 and 2007/08 at one CFE, collecting secondary data and primary data from students and module deliverers. In this second stage relevant students from these cohorts are followed and 2009/10 has been added to the study. As the programme has been taken up by other CFEs the study was extended to include three colleges in addition to the original.

To see the topic from the perspective of the participant and to understand how and why they come to have this perspective (King, 2004), qualitative interviews and focus groups were used to gather primary data. Secondary data was collected from the CFEs to enable analysis of the demographic profile of students on the module, pass rates and the destination of those completing the module. Applicant and conversion statistics from Teesside University were also analysed as well as progression data for relevant students at TUBS (Teesside University, 2010).

To obtain student opinions on the current provision, six focus groups were held with students studying the module. To allow for comparison with previous cohorts and between current providers two groups were held at college $A$ and $B$, and one each at college $C$ and D. Apart from one CFE where only 3 students were completing the module, the groups contained 6-10 students (43 students). Students were questioned on information sources related to the modules, their expectations, and module strengths and weaknesses. The decision to progress to HE was also explored. The views of the institutions were gathered 
through in-depth interviews with deliverers in each of the four colleges, the module leader at TUBS and senior management at three of the CFEs (8 interviews). As well as module strengths and weaknesses, topics discussed with staff included student feedback and the relationship between the CFE and university, particularly with regard to support and administration. To investigate the transition to $\mathrm{HE}$, in-depth interviews were carried out with three students who had progressed to HE (one in each year of undergraduate study).

Focus groups and interviews were taped and the data transcribed and analysed by both researchers to ensure inter-relater reliability. To enable comparisons to be made between CFEs, a cross-case analysis (Huberman and Miles, 1998) was carried out on the data. As the student experience has been reported elsewhere (Bussell and Mulcahy, 2009) the findings below concentrate on the qualitative data collected from staff involved in the collaborative partnership. The key points from the findings have been incorporated into a model to highlight the main areas of consideration for collaborative working between FE and HE.

\section{Findings}

The introduction of PHE has been a great success in terms of partnership take-up and participation, and has provided CFEs with an innovative skills module. It has cemented the existing work between the local colleges and the university. Moreover, it has been of great benefit in widening participation in HE and enhancing students' ASC. It has also proved to be a useful tool in the recruitment and retention of local students for Teesside University.

Colleges are keen to deliver this module and work in partnership with the university, offering the course to increasing numbers of students, which demonstrates how well partners work together:

Working with the university is good and it is good in a way that it's not too obtrusive as well. It's kind of just that mutual respect that, yes, you know what you're doing so we'll just let you get on and do it but we're here if there are any issues.

At the initiation stage colleges were very motivated. The original idea to collaborate in delivering the spiky module came from a CFE. As more colleges came on board, at the 
clarification and implementation stage delivery mode, delivery location, source of tutors, group size and optionality has been customised to suit each college (the decision often driven by resources rather than pedagogy). This indicates the flexibility of this module, but there is consensus that the module is most effective when it is an integral part of the programme taken by all students with some input by university tutors and attendance on the university campus:

I think it adds a fantastic amount of value because most of the programmes don't have an element of study skills in them and so you pinch a bit off your unit to do this but this, I've been able to integrate it throughout the programme and so it's definitely been a benefit, it's improved $100 \%$ for most of them.

More times going to the university I think would help...We come to the university. Our students get a research centre induction and they get a library card. They feel part of the university...They do an academic essay under academic rigour and relatively strict university guidelines. We take them to the university and they get to use the university resources.

The flexibility of the module has been one of the drivers for its growth. It is considered to be more appropriate and adaptable than other skills modules as it covers more transferrable skills and allows time to develop study skills alongside the necessary competences for studying at HE level:

It can be discreet if you want or it can be embedded as well so it's the flexibility of it really that's good.

However, its greatest strength is seen to be its role in widening participation in HE, emphasising that studying at university is an option for students from an area characterised by long-established work roles and traditional forms of identity where there is no history of family or friends progressing to HE; the focus of the module very much the needs of the student. The benefits beyond improving study skills, in raising aspirations, are apparent to tutors and students: 
In my group none of them have anybody in their family who've gone onto degrees. They all have the opinion that universities are for rich intelligent people. Now...we're breaking those barriers down.

I probably wouldn't have come if I hadn't have done that module...It just really changed my mind. It made it less scary...just being here it did and I'm quite glad it did.

A major difference from Stage 1 of the study is the improvement in college tutors' endorsement of the module. While there continues to be differences between colleges in the level of support given to deliverers by their senior management, the scepticism of colleagues evident in our previous research (Bussell and Mulcahy, 2009) has all but disappeared. However, the module title was a concern in the first stage of the study and is still being raised. Although unhappy with the names allocated by the university there is no consensus on a more appropriate label. Positioning it as a skills module makes it easier to incorporate into the curriculum, with students seeing it as an integral part of their course rather than an add-on, but this impacts on both staff and students' understanding of the module aims.

The findings demonstrate that the relationship between the university and local CFEs is excellent on an interpersonal level, supportive and based on mutual respect. However, the findings show that the parties hold slightly different views. The university appears to have interpreted the relationship as a collaborative one in that the organisations work together but administration sometimes resembles a franchise in that the colleges see themselves having to follow rules and guidelines set down by the university. As the operation is under the university's Higher Education Business Partnership (HEBP) banner, the deliverers can see they are part of a partnership. Some are content to be junior partners but it is apparent that some feel this should mean working together as equals not imposing one organisation's systems on another. It is acknowledged that the university's procedures sometimes improve the process but there exists the implicit assumption that university practices are superior, the ones to be followed. As PHE is a university module it is unavoidable that it is processed through university regulations but collaboration requires blended systems as well as blended learning: 
If you actually discussed assessment, not as in this is how you mark according to our criteria but actually let's explore the whole issue of assessment. If we looked at it in terms of issues of equality and diversity and the practice of that across FE and $\mathrm{HE}$, that would be meaningful. How could we support you? You've got this. Now that would all be meaningful.

The impression of a franchise rather than a true partnership is strengthened when examining learning and teaching strategies. At the start of the academic year the university module leader holds a planning meeting. Teaching material and assessments developed by university lecturers are provided to CFE tutors. Some items used by partners are made available. Tutors tend to use a combination of these plus their own material developing a knowledge partnership between the parties which is seen by them to be a strength of the relationship. For effective partnership, working members have to feel part of a consortium or partnership group. Tutors are generally happy with the arrangements but there is a feeling that there should be greater sharing of material and more consultation in course design, questioning the extent that this is a true partnership:

Are we considered to be academically and intellectually capable and valued and therefore working in partnership?

As more organisations are now delivering the module there is variation in how aware management and deliverers are of what is happening throughout the partnership, particularly in terms of best practice. The university stages an annual conference to which all partner colleges are invited, providing an opportunity to meet and discuss new initiatives with colleagues from other institutions and with university staff. Also CFE staff are encouraged to attend end of year Boards at the university at which this module is discussed to give the partners a voice in progression and award decisions, but most staff (and some managers) consider these meetings to be over long and see little value in their presence. Further staff development is left to each partner.

The relationship between the university and its partners is, therefore, quite complex. Although in some areas the university has very much taken the lead there is a perception that the university is not always fulfilling its side of the partnership: 
At the beginning of the year there is the expectation and the intent that you'll come and do all these visits here and you'll take the students to the library, visit or we'll get people from the university to come and watch their presentations but they never...The visits didn't transpire. But that didn't really affect us. We were just getting on with it.

Visits to the university campus and input from university lecturers were built into the module specification but the university's contribution is developing into a regulatory role (supervising content and material and imposing quality systems). From the quote above it can be seen that college staff and management were quite pragmatic about this, acknowledging that to some extent they had created this change in the relationship. For example, some staff are reluctant to bring their students to the university campus viewing the bureaucracy and rearranging timetabled commitments as a greater hurdle than the benefits students may gain. Resources played a key role for all parties:

If we come down to the university we have to provide cover for our classes. And we have to arrange a bus. And who pays for the bus?

Branding of the module, its flexibility and growth, combined with a change in the university's input, is affecting the focus of the module and the working of the partnership. In some colleges PHE is seen as just an alternative skills module. It is apparent that the module is most valuable where the parties are working as a team sharing delivery and running sessions on the university campus as originally designed. The resource implications of an increasing number of students visiting the campus has affected this element but, where this has lapsed, it needs to be reintroduced and managed to ensure one of the key benefits of the module, easing student transition to HE, is not lost:

You just think 'Oh my God, it was ok when there was 15 of them', you could just come along. With 180 students it's the logistics of it. That would be a couple of busloads wouldn't it?

A key issue throughout the study is responsibility for resources. The operation of the module relies a great deal on the goodwill of individual tutors. In a partnership there is often the expectation that the other party should provide the means to run the programme effectively. It remains somewhat unclear in this instance where accountability lies. Under current funding arrangements the ratio is $75 \%$ to CFEs and $25 \%$ to Teesside University, 
yet the university is usually expected to take the lead. In a time of cut backs in the education budget this matter must be openly addressed and agreed by all parties.

Ongoing interest in the module would indicate that it is going to expand. This may put pressure on the collaborative nature of the project. The findings show that recent growth is already changing the relationship. The excellent interpersonal bonds which have developed between the parties are likely to be affected as more join the programme and individuals move on. A reliance on the enthusiasm and goodwill of the current team will be insufficient if the benefits of the module are to continue. The original concept of this module has been effectively operationalised by the partners but there is little evidence of a strategic focus which is required to take the project forward.

The message from these findings is that in a collaborative venture there should be joint working at all stages. While an attraction of PHE for the colleges is its link to the Teesside University brand, working within a collaborative framework necessitates a mutual respect, selecting best practice and the most appropriate methods. The main influence on the collaborative process should be knowledge and expertise, wherever this resides.

\section{Conclusion}

This study evaluates a module delivered through collaboration between a university and its FE partners. The issues highlighted in the findings demonstrate a successful collaborative partnership which has enabled the original aims of the module to be recognised. Key findings from this stage of the research reveal the student experience to be central to the module and all those involved in its operation; this has been achieved through a blended learning approach. Colleges are keen to collaborate with the university and be guided as to the learning and teaching approach, quality issues, systems, operationalisation and positioning of the module. Systems and operationalsiation provide challenges for both the university and some colleges but offer an opportunity to share best practice across the colleges. Although the university is expected to take ownership of the programme, funding (and hence resources) do not automatically follow. This should be reviewed for the future so sufficient support is given to colleges without it being over onerous for the university. 
The flexibility and adaptability of the module has been a driver for its adoption by colleges across the Teesside area. Colleges could choose how they would prefer to deliver the course which gave them a certain degree of autonomy from the university. However, the essence of the programme must be maintained. For example, college students attending the university to allow them to engage in the student university experience. The success of the module needs to be addressed in future research from the perspectives of both 'hard' and 'soft' measurements of achievement, quantified and assessed over time.

Relationships take time to develop and this burgeoning relationship between students, colleges and the university is one to be cultivated. These findings have been incorporated into a Collaborative Partnership Model illustrated in Figure 1 below.

Figure 1. Collaborative Partnership Model.

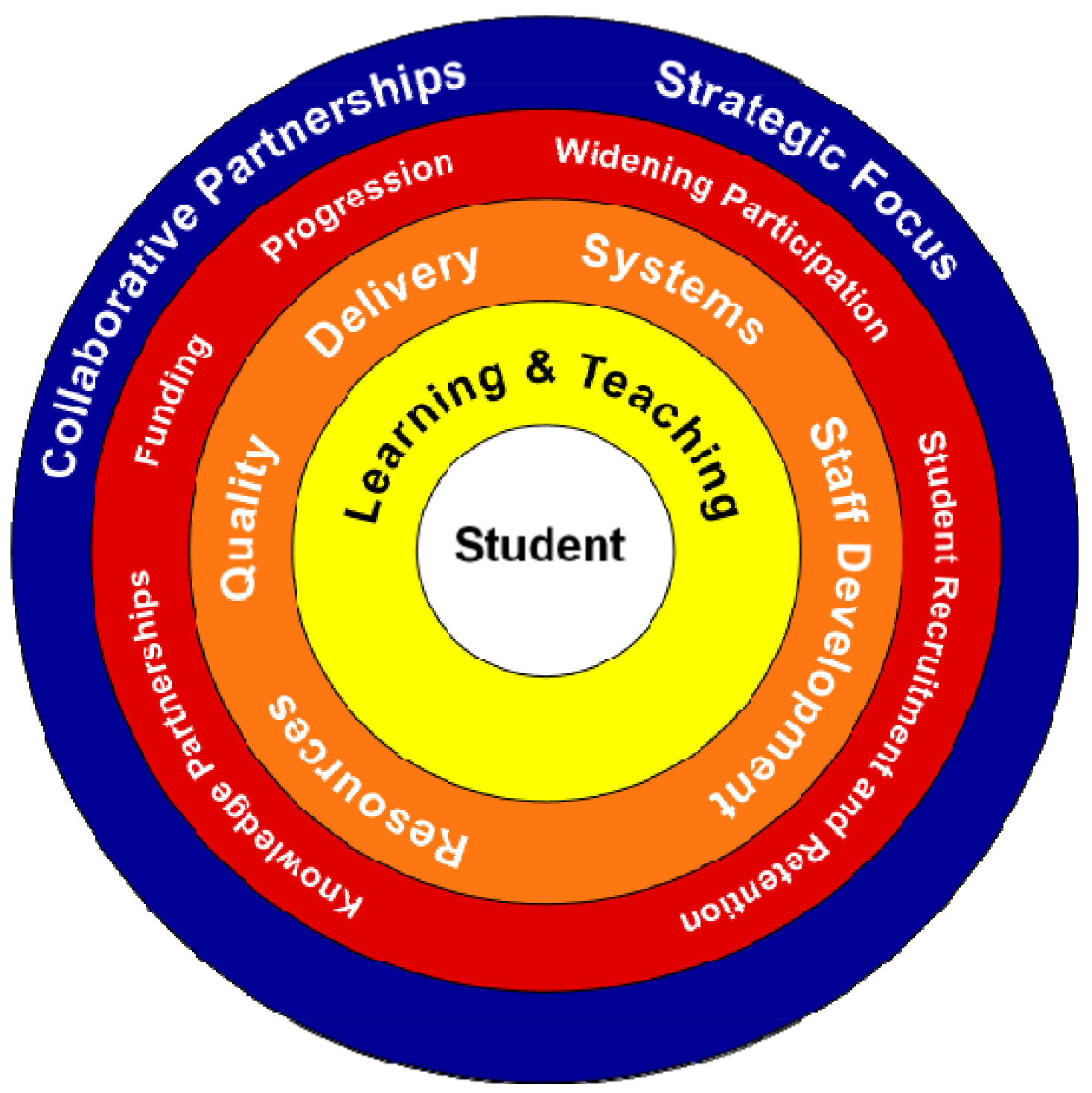


The benefits of this module to the student identified in the findings place the student at the centre of the model. For both the university and colleges, student needs are the focus of the learning and teaching strategy which is customised to meet the requirements of students within each partner organisation. It has been shown above how this customisation is achieved through the mode of delivery, resources, quality procedures and systems which are enhanced by staff development and the relationship between the partner institutions (highlighted within the next ring). For successful collaboration the elements in this layer of the model must be driven by student need to maintain the student focus of the venture but also to retain partnership working (and avoid domination by any member).

For the partnership to develop and continue in a changing climate, the findings indicate that a strategic focus is required. Therefore, the model also takes account of macro environmental factors which impact on the project. In this study the external drivers which emerged were knowledge partnerships, alternative progression routes and retention strategies developed to achieve Government and institutional policies of widening participation and increased student recruitment. Although not raised by participants in the study, funding has been added to the model as this has become a key issue since this stage of the research was completed for both students and the institutions involved. Changes to the funding of HE will necessitate innovative projects (such as the example examined here) to encourage participation in HE. The strengths of this module and its role in the ever important widening participation agenda remain.

The findings show that the strength of the collaboration between Teesside University and its partners is that it remains student focussed, particularly in relation to skills development. However, this aspect of the module is gaining predominance over easing student transition to HE (which was originally a key aim of the module). This learning objective and the learning and teaching strategy (the second ring in our model) are being affected by the elements in the next layer. Mode of delivery is driven more by resources than student need. Also, there is less input by university staff and fewer sessions at the university campus. To continue its success this collaborative venture must ensure the student remains at the centre of the learning and teaching strategy. Systems and quality are increasingly led by Teesside University whereas staff development is left to the colleges. In some areas the university is being seen as the lead rather than as a partner. Working in true partnership at this level of our model is essential to maintain effective 
collaboration. The interaction between partners and excellent relationships are enabling the partners to work together towards achieving the organisational goals highlighted in the fourth ring of our model but it is clear that a long-term strategic focus is required if this is to carry on.

The researchers aim to continue with the longitudinal study of this module in order to complete its evaluation. Further research will also enable a deeper understanding of collaborative working. In addition they intend to test this model in other examples of FE and HE partnerships.

\section{References}

Bennett, R. (2009) 'Academic self-concept among business students in a recruiting university: definition, measurement and potential effects', Journal of Further and Higher Education, 33(2), pp. 141-156.

Bussell, H. and Mulcahy, L. (2009) 'Bridging the gap between transition from FE to HE: Evaluation of a 'spiky profile", Higher Education Academy Annual Conference. University of Manchester 30 June -2 July.

Buys, N. and Bursnall, S. (2007) 'Establishing university-community partnerships: process and benefits', Journal of Higher Education Policy and Management, 29(1), pp. 7386.

Department for Education and Employment (DfEE) (2000) Higher education funding for 2001-02 and beyond. Available at: http://www.hefce.ac.uk/news/HEFCE/2000/funding.htm (Accessed: 3 March 2011).

Department for Innovation, Universities and Skills (DfIUS) (2001) Raising standards. London: DIUS.

Department for Innovation, Universities and Skills (DfIUS) (2003) The future of higher education, (Cm 5735). London: HMSO. 
Department for Innovation, Universities and Skills (DfIUS) (2008) Participation rates in higher education: academic years 1999/2000-2006/2007 (provisional). DIUS SFR 02/2008. London: DfIUS.

Hastad, D.N. and Tymeson, G. (1997) 'Demonstrating visionary leadership through community partnerships', Journal of Physical Education, Recreation and Dance, 68(5), pp. 45-51.

Higher Education Funding Council for England (2006) Widening participation: a review. London: HEFCE.

Higher Education Statistics Agency (2008) Performance indicators in higher education. Available at: http://www.hesa.ac.uk/index.php/content/category/2/32/129/ (Accessed: 4 March 2011).

Huberman, A.M. and Miles, M.B. (1998) 'Data management and analysis methods', in Denzin, N.K. and Lincoln, Y.S. (eds.) Collecting and interpreting qualitative materials. California: Sage, pp. 179-210.

Jary, D. (2008) 'The continued importance of widening participation', Widening Participation and Lifelong Learning, 10(1), pp. 1-2.

King, N. (2004) 'Using interviews in qualitative research', in Cassell, C. and Symon, G. (eds.), Essential guide to qualitative methods in organizational research. London: Sage, pp. 11-22.

Kluth, P. and Straut, D. (2003) 'Do as we say and as we do: teaching and modelling collaborative practice in the university classroom', Journal of Teacher Education, 54(3), pp. 228-240.

Michie, F., Glachan, M. and Bray, D. (2001) 'An evaluation of factors influencing the selfconcept, self-esteem and academic stress for direct and re-entry students in higher education', Educational Psychology, 21(40), pp. 455-72. 
Rushford, J. (2004) Working with institutions to embed participation: discussion paper. Available at: http://www.hefce.ac.uk/widen/strategy/ (Accessed: 4 March 2011).

Sargent, L. and Waters, L. (2004) 'Careers and academic research collaborations: an inductive process framework for understanding successful collaborations', Journal of Vocational Behaviour, 64(2), pp. 308-319.

Smith, D. and Bocock, J. (1999) 'Participation and progression in mass higher education: policy and the FHE interface', Journal of Education Policy, 14(3), pp. 283-299.

Stuart, M. (2003) Widening participation; the changing agenda. HEA. Available at: http://www.ukcle.ac.uk/resources/directions/previous/issue6/access/ (Accessed: 4 March 2011).

Teesside University (2008) Widening participation strategy, 2005-2009. Internal document. Middlesbrough: Teesside University.

Teesside University (2010) Teesside University registry data on feeder institutions. Internal document. Middlesbrough: Teesside University.

\section{Author details}

Helen Bussell is Principal Lecturer in Marketing at Teesside University Business School. She leads courses in not-for-profit marketing at undergraduate and postgraduate level and for managers working in the public and third sectors as well as postgraduate Research Methods. Her main research interests are in marketing in the public and third sectors and widening participation. She has published a number of academic papers on consumer behaviour in education and on volunteer recruitment and retention.

Lesley Mulcahy is Senior Lecturer in Marketing at Teesside University Business School. In partnership with the North East Chamber of Commerce, she leads Teesside University's FdA in Leadership and Management which won The Times Higher 
Award for Outstanding Employer Engagement Initiative 2009/10. Her main research interests are leadership, employer engagement and widening participation. 